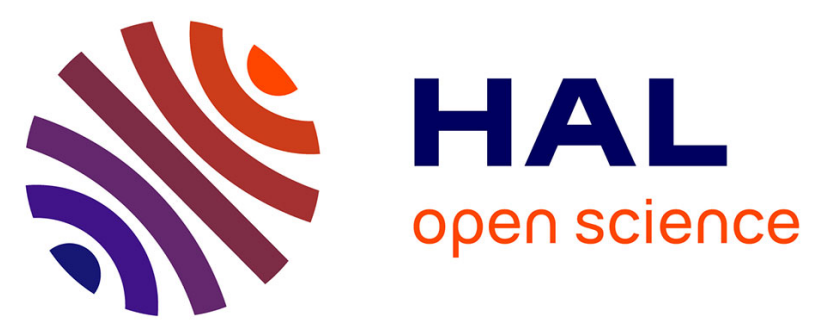

\title{
Three-dimensional reconstruction using stereoradiography for evaluating adult spinal deformity: a reproducibility study.
}

Emmanuelle Ferrero, Renaud Lafage, Shaleen Vira, Pierre-Yves Rohan, Jonathan Oren, Edward Delsole, Pierre Guigui, Frank Schwab, Virginie

Lafage, Wafa Skalli

\section{To cite this version:}

Emmanuelle Ferrero, Renaud Lafage, Shaleen Vira, Pierre-Yves Rohan, Jonathan Oren, et al.. Threedimensional reconstruction using stereoradiography for evaluating adult spinal deformity: a reproducibility study.. European Spine Journal, 2016, 26, pp.2112-2120. 10.1007/s00586-016-4833-5 . hal-02489064

\section{HAL Id: hal-02489064 \\ https://hal.science/hal-02489064}

Submitted on 24 Feb 2020

HAL is a multi-disciplinary open access archive for the deposit and dissemination of scientific research documents, whether they are published or not. The documents may come from teaching and research institutions in France or abroad, or from public or private research centers.
L'archive ouverte pluridisciplinaire HAL, est destinée au dépôt et à la diffusion de documents scientifiques de niveau recherche, publiés ou non, émanant des établissements d'enseignement et de recherche français ou étrangers, des laboratoires publics ou privés. 


\title{
Three-dimensional reconstruction using stereoradiography for evaluating adult spinal deformity: a reproducibility study
}

\author{
Emmanuelle Ferrero $^{1,2} \cdot$ Renaud Lafage $^{3} \cdot$ Shaleen Vira $^{3} \cdot$ Pierre-Yves Rohan $^{2}$.

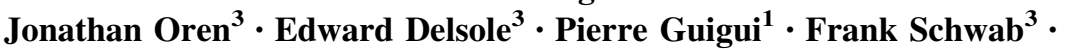 \\ Virginie Lafage $^{3} \cdot$ Wafa Skalli $^{2}$
}

\begin{abstract}
Purpose In addition to the sagittal alignment, impact of transverse plane parameters (TPP) and rotatory subluxation on patients reported outcomes were highlighted. One of the hypotheses for genesis of degenerative scoliosis is disc degeneration with increased axial vertebral (AVR) and intervertebral rotation (AIR). Therefore, TPP analysis at early stage of the scoliosis seems of particular interest. This study aims at assessing reliability of tridimensional (3D) reconstructions of adult spinal deformity (ASD) patients. Methods Thirty ASD patients underwent biplanar radiographs and were divided into two groups (Cobb angle $>30^{\circ}$ or $<30^{\circ}$ ). Spinal parameters and TPP (apical AVR, AIR of upper and lower level of main curve) were measured. Four operators performed 3D reconstructions twice. Intra and inter-observer reliabilities were analyzed using ISO standard 5725-2, to quantify the global standard deviation of reproducibility $\left(S_{\mathrm{R}}\right)$.

Results Mean Cobb angle was $31^{\circ}$, mean age 55 years (70\% of female). Mean values of apical AVR, upper and lower level AIR were, respectively, $16^{\circ} \pm 15^{\circ}, 6^{\circ} \pm 6^{\circ}$ and $5^{\circ} \pm 5^{\circ}$. Spinopelvic parameters $S_{\mathrm{R}}$ were below $4.5^{\circ}$. For Cobb angle $<30^{\circ}, S_{\mathrm{R}}$ was $7.8^{\circ}, 9.6^{\circ}, 4.5^{\circ}$ and $4.9^{\circ}$, respectively, for AVR apex, torsion index, upper and lower
\end{abstract}

Emmanuelle Ferrero

emmanuelle.ferrero@aphp.fr

1 Department of Orthopaedic Surgery, Hopital Européen Georges Pompidou, APHP, Paris V University, 20 rue Leblanc, 75015 Paris, France

2 Laboratoire de biomécanique Georges Charpak, Ecole nationale supérieure des arts et métiers, 75013 Paris, France

3 Department of Orthopaedic Surgery, Hospital for Special Surgery, New York, NY, USA
AIR. Reliability was worse in the group of patients with Cobb angle above $30^{\circ}$.

Conclusions 3D analysis was reliable for Cobb and sagittal parameters. 3D analysis for TPP was reproducible when Cobb is below $30^{\circ}$. However, uncertainty is larger for Cobb above $30^{\circ}$. Nevertheless, 3D reconstructions could help surgeons to anticipate onset of rotatory subluxation while assessing axial rotation evolution for small deformity and choose best delay for surgical treatment.

Keywords Adult spinal deformity - Tridimensional analysis - Transverse plane parameters - ISO standard . Reproducibility

\section{Introduction}

Scoliosis is a three-dimensional deformity, as such its radiographic analysis needs to be performed conjointly in the coronal, sagittal and axial [1]. Historically, the Cobb angle has been considered as the main parameter to describe the severity of scoliosis, with the most severe deformity at the apical vertebra [2-4]. In the past decades, the importance of analyzing radiographic images in the sagittal plane has been emphasized in light its correlation with pain and disability is now well recognized [5-7]. While there is a paucity of data regarding the analysis of the axial plane in the setting of adult spinal deformity (ASD), rotatory subluxation has been found to be associated with patient reported outcomes [6]. Since most of the clinical investigations rely on 2D images, numerous methods have been developed to estimate the vertebral axial rotation based on the projection of the pedicles or spinous process on coronal X-ray [8-11]. However, in severe deformity measurement of pedicle shadow does not 
correspond to the true shape [12]. Since, one of the hypotheses for genesis of degenerative scoliosis is disc degeneration with increased axial vertebral (AVR) and intervertebral rotation (AIR), transverse plane analysis at early stage of the scoliosis seems of particular interest.

In an effort to characterize the axial plane, the radiographic evaluation of ASD patients is often complemented by an MRI or CT scan examination. One of the limitation common to these two modalities relates to the fact that the acquisition is not performed in a weight baring position, and therefore, can lead to a failure to identify patterns of deformity that could result in pain or functional impairments. In addition, the radiation exposure during CT scan acquisition may be an issue in the setting of longitudinal investigations [13]. Since 2007, a new imaging system, available in clinical practice, permits to obtain low-dose full-spine biplanar stereoradiography in a standing position. Based on a dedicated algorithm, these biplanar images can be analyzed to generate 3D reconstructions of the spine with transverse plane analysis $[14,15]$. The measurements validity of this stereoradiographic system has been reported in pre- and post-operatively in the setting of idiopathic scoliosis, as well as the clinical relevance of 3D analysis with transverse plane [3, 16, 17].

To our knowledge no validity study of this 3D reconstruction software has been performed in ASD. Aim of the current study was to assess the reliability of the 3D measurement with stereoradiography images in ASD patients without previous spinal surgery.

\section{Methods}

\section{Patients selection}

In this retrospective single center study, thirty ASD patients randomly selected from an existing 3D database were included after institutional review board approval. Inclusion criteria were ASD patients, primary cases with different curves severity, with a main Cobb angle at least of $10^{\circ}$. To limit sample bias and provide a representative range of ASD, the 30 patients were recruited among different value of axial intervertebral rotation (AIR): 10 patients with AIR below $5^{\circ}, 10$ patients with AIR between $5^{\circ}$ and $10^{\circ}$, and 10 patients with AIR above $10^{\circ}$. Exclusion criteria included previous spinal surgery with instrumentation, diagnoses of scoliosis other than ASD (i.e., neurologic, congenital, traumatic, neoplastic).

\section{Stereoradiographic system}

As part of routine clinical practice, patients underwent lowdose biplanar full-spine stereoradiographic images with
EOS $\odot$ system (EOS imaging, Paris, France). EOS is a slot scanning radiologic device that consisted of two orthogonal $\mathrm{X}$-ray sources, allowing simultaneous acquisition of two images, avoiding image distortion [18, 19]. Radiography was performed on a standardized protocol: patient upright, with horizontal gaze, and fingers on the clavicles to avoid superimposition of the arm on the spine [20, 21]. All images included at least the skull to the femoral heads.

\section{D parameters}

Four observers performed independently the 3D measurements two times (a week apart), for each of the thirty patients (240 reconstructions). Among the four observers, three were spine surgeons (one was familiar with the $3 \mathrm{D}$ measurement method) and one was a medical student.

3D spinal reconstructions used SterEOS $\odot$ software, version 1.2.1 (EOS imaging, Paris, France) based on identifiable anatomic points. The end vertebrae for each curve of the deformity were defined as described by Cobb with the most tilted vertebrae on coronal $\mathrm{X}$-rays, by an experienced observer [22]. The apical vertebra was defined as the most rotated vertebra in the axial plane. The four observers used the same apex, upper and lower levels for all the patients. In the sagittal plane, spinal parameters were measured with L1S1 lordosis, T1T12 and T4T12 kyphosis, and pelvic parameters with pelvic incidence (PI), pelvic tilt (PT), and sacral slope (SS). Of note, a negative PT corresponded to a pelvic anteversion and negative values for T1T12 or T4T12 meant that the thoracic area was lordotic (Fig. 1). Coronal parameters included Cobb angle of the thoracic curve (Cobb 1), the thoraco-lumbar curve (Cobb 2) and the lumbar curve (Cobb 3). Main Cobb corresponded to the largest of the three curves. The 3D vertebral and intervertebral orientations were expressed in the axial, frontal and sagittal planes. The relative intervertebral rotation was defined as superior vertebral rotation with respect to the underlying vertebra. Transverse plane parameters included apical axial vertebral rotation (AVR) and axial intervertebral rotation (AIR), with AIR of the upper level of the main curve (upper AIR) and AIR of the lower level of the curve (lower AIR). The torsion index (sum of the AIR within the main curve) was also computed [23] (Fig. 2).

\section{D reconstructions}

Based on parametric model previously described [24], 3D reconstructions of the spine were performed. The first step was to spot the sacral endplate with a line and the acetabuli with two circles. Thus, the patient plane can be defined 

parameters measurements
Fig. 1 Coronal and sagittal
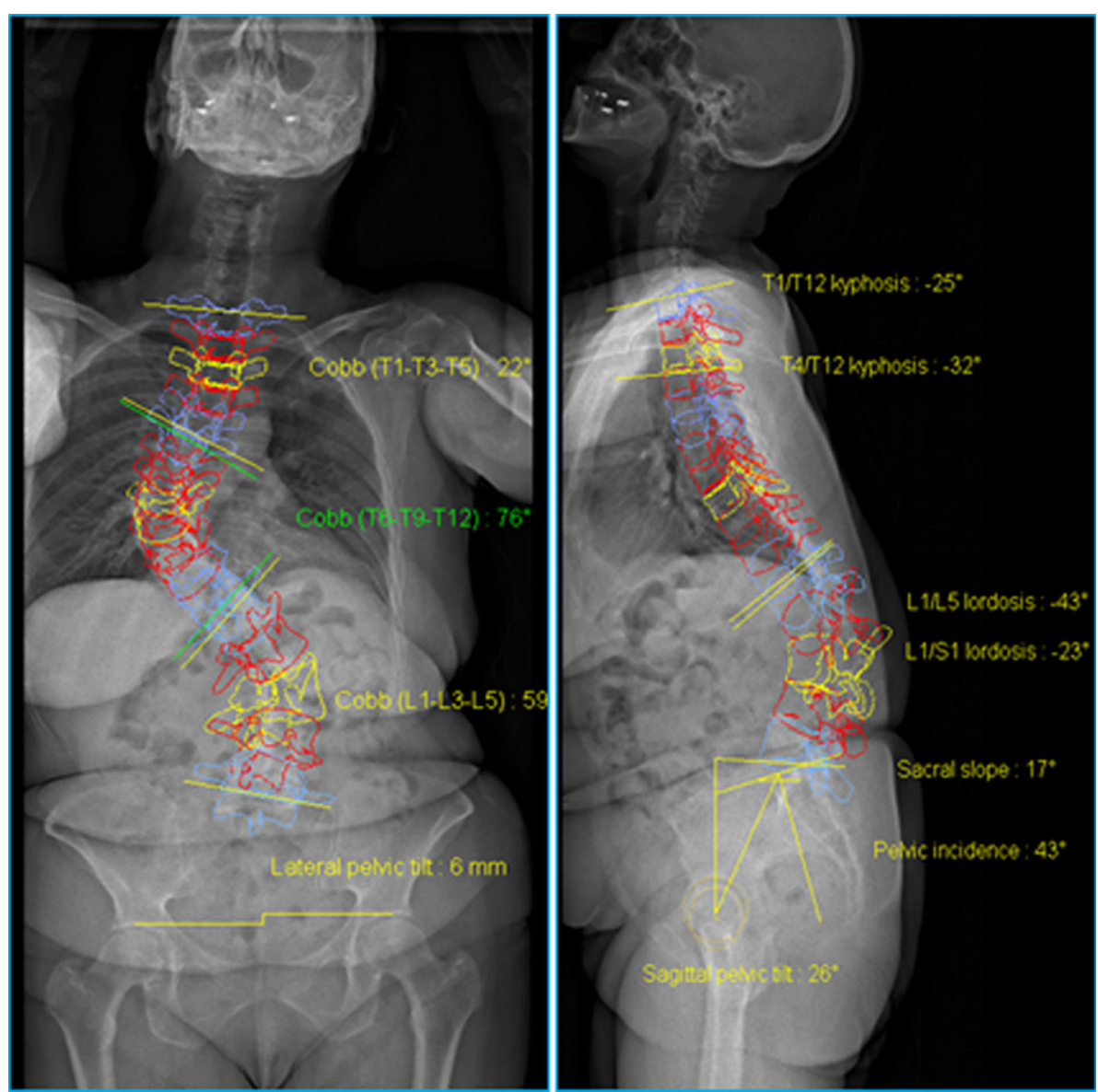

Fig. 2 Transverse plane parameters

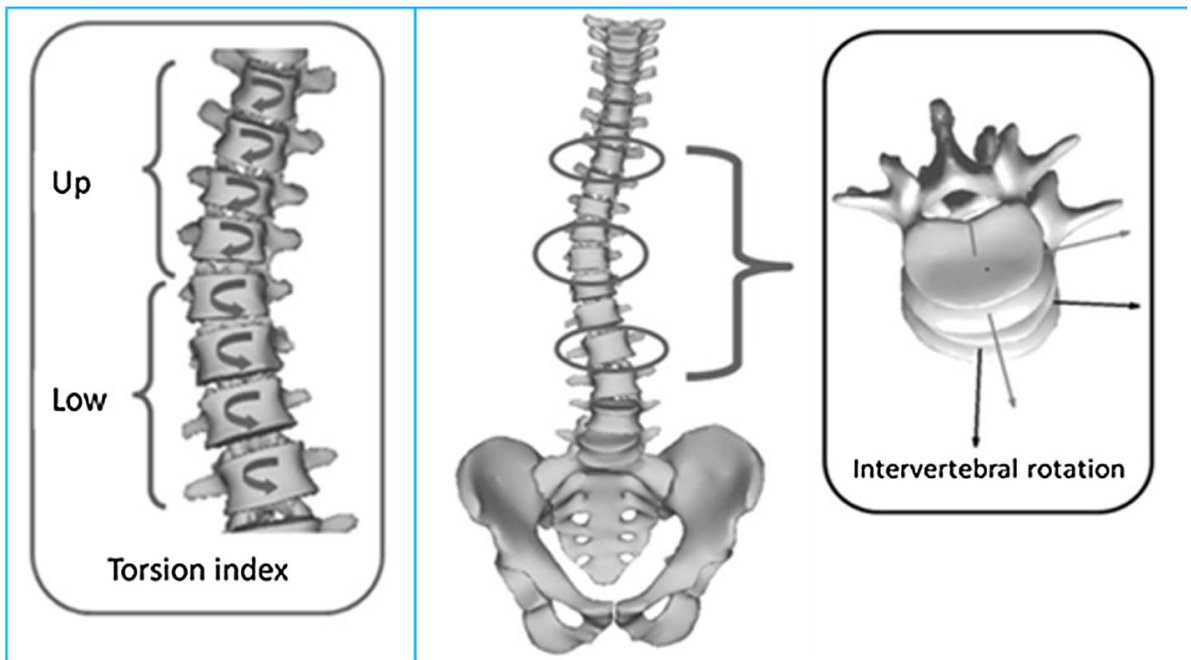

with the central hip vertical axis as described by the scoliosis research society [25]. Second, the global shape of the spine and the lower endplate of L5 are located on sagittal and coronal view. Third, 3D model of the spine was generated using a combined geometric and statistical model [26]. Then, each vertebra from T1 to L5 was accurately adjusted using three control points on the upper and lower endplates and using an ellipsis for each pedicle. Finally, the observer checked the adjustment of each landmark.

\section{Statistical analysis}

First, a descriptive analysis of the cohort was performed in terms of coronal, sagittal and axial 3D parameters. Then, 
according to International Standardization Organization (ISO) recommendation intra-observer and inter-observer reliabilities were analyzed [42]. Reliability of the measurements was computed using ISO standard 5725-2, which allows uncertainty estimation by the calculation of the variance of reproducibility $\left(S_{\mathrm{R}}^{2}\right)$ which is the sum of the mean of variance of intra-observers measurements $\left(S_{\mathrm{r}}^{2}\right)$ and of the variance of inter-observers measurements $\left(S_{\mathrm{L}}^{2}\right)$ :

$S_{\mathrm{R}}^{2}=S_{\mathrm{r}}^{2}+S_{\mathrm{L}}^{2}$.

As recommended by ISO standard, potential outliers were identified using Bland and Altman graphs [27] (Fig. 3). A thorough review of the measurements was performed by an expert board and measurement errors inherent to observers or inherent to the method were identified. Outliers with errors resulting from the method were kept, whereas a third round of measurement was performed for patients with aberrant error made by observers.

Intraclass coefficient of correlation (ICC) was also calculated as another mean to assess intra-observer repeatability and inter-observer reproducibility. An ICC greater than 0.91 was considered as very good, an ICC between 0.90 and 0.71 as good, an ICC between 0.70 and 0.51 as moderate and an ICC lower than 0.50 as poor [28]. To analyze the reproducibility depending on the severity of the deformity, a subgroup analysis was performed. Patients were divided in two groups according to main Cobb angle measurements: above or below $30^{\circ}$. Data were statistically analyzed using Stata software 13.0 (Statacorp, College Station, Texas) and Matlab (Mathworks, Natick, Massachusetts).

\section{Results}

\section{Descriptive analysis}

Mean age of the 30 patients was 55 (SD:13) years, with a majority of female (70\%). The deformity was mild with a mean Cobb angle of $12^{\circ}$ for thoracic curves (Cobb 1), $25^{\circ}$ for thoraco-lumbar curves (Cobb 2) and $27^{\circ}$ for lumbar curves (Cobb 3) with the largest curve of $79^{\circ}$. AVR apex was higher for lumbar curves. Range of AVR apex for thoracic, thoraco-lumbar and lumbar curve were, respectively, small, moderate and very large $\left(0^{\circ}-98.9^{\circ}\right)$ (Table 1$)$.

Mean Cobb angle of the main curve was $31^{\circ}$. Transverse plane parameters of the main curve were $15.7^{\circ}, 29.9^{\circ}, 6.2^{\circ}$ and $4.8^{\circ}$ for, respectively, AVR apex, torsion index, upper and lower AIR (Table 2). The most important axial intervertebral rotation was reported at $\mathrm{L} 2 \mathrm{~L} 3\left(8.3^{\circ}, \mathrm{SD}: 8.9^{\circ}\right)$ and L3L4 $\left(7.3^{\circ}, \mathrm{SD}: 8.7^{\circ}\right)$. The widest range of intervertebral rotation was observed for L3L4 AIR: $0^{\circ}-68^{\circ}$.
The mean values of sagittal spinal and pelvic parameters are reported in Table 3 . The range of PI was very large with a mean value of $54.9^{\circ}$. The mean PT was $20.5^{\circ}$. Mean lumbar lordosis was $47.0^{\circ}$ and mean T1T12 thoracic kyphosis was $38.2^{\circ}$.

\section{Reliability analysis}

Sagittal parameters reliability was good with a $S_{\mathrm{R}}$ between $3^{\circ}$ and $4^{\circ}$ and ICC corresponded to a very good reproducibility $(>0.930)$. In terms of Cobb angle and AVR apex, $S_{\mathrm{R}}$ was below $5^{\circ}$ for Cobb angles, around $5^{\circ}$ for AVR apex of the thoracic and thoraco-lumbar curves, almost $10^{\circ}$ for AVR apex of the lumbar curve.

Reliability of transverse plane parameters of the main curve was reported in Table 4. $S_{\mathrm{R}}$ (with one standard deviation) results of transverse plane parameters were different for each patient group according to Cobb angle (Table 4). For Cobb angle $<30^{\circ}, S_{\mathrm{R}}$ was $7.8^{\circ}, 9.6^{\circ}, 4.5^{\circ}$ and $4.9^{\circ}$, respectively, for AVR apex of the main curve, torsion index, upper and lower AIR. Reliability was worst in the group of patients with Cobb angle above $30^{\circ}$. In terms of intervertebral rotation, measurements repeatability and reproducibility was lower for axial intervertebral rotation than coronal or sagittal intervertebral rotation.

\section{Discussion}

Measurement of radiographic parameters is essential to understand and treat patients with spinal deformity. More recently, the importance of 3D analysis has been emphasized, especially transverse plane parameters $[12,23,29-32]$. In the current study, the reliability of 3D reconstructions of the vertebral column of ASD patients was quantitatively assessed yielding new data on transverse plane parameters reproducibility.

In the past decade, impact of sagittal alignment on patients reported outcomes has been highlighted [5-7]. Besides of sagittal parameters, significant correlations were observed between patients reported outcomes and 3D parameters such as vertebral rotation [33]. In a previous work, the authors demonstrated that rotatory subluxation in ASD patients was significantly associated with low back pain and radiculalgia [32]. However, in this study, rotatory subluxation was defined with lateral listhesis measurement without axial rotation uncertainty evaluation. They also observed that $10 \%$ of the patient had axial rotation above $10^{\circ}$ without visible lateral listhesis on 2D radiographic images. Consequently, $3 \mathrm{D}$ evaluation of ASD seems essential. Moreover, the intervertebral disc is key to understanding spine biomechanics, and it is often involved in the cascade leading to spinal deformities $[34,35]$. As a matter of fact, one of the 
Fig. 3 Example of Bland and Altman graphs with and without errors inherent to the observers
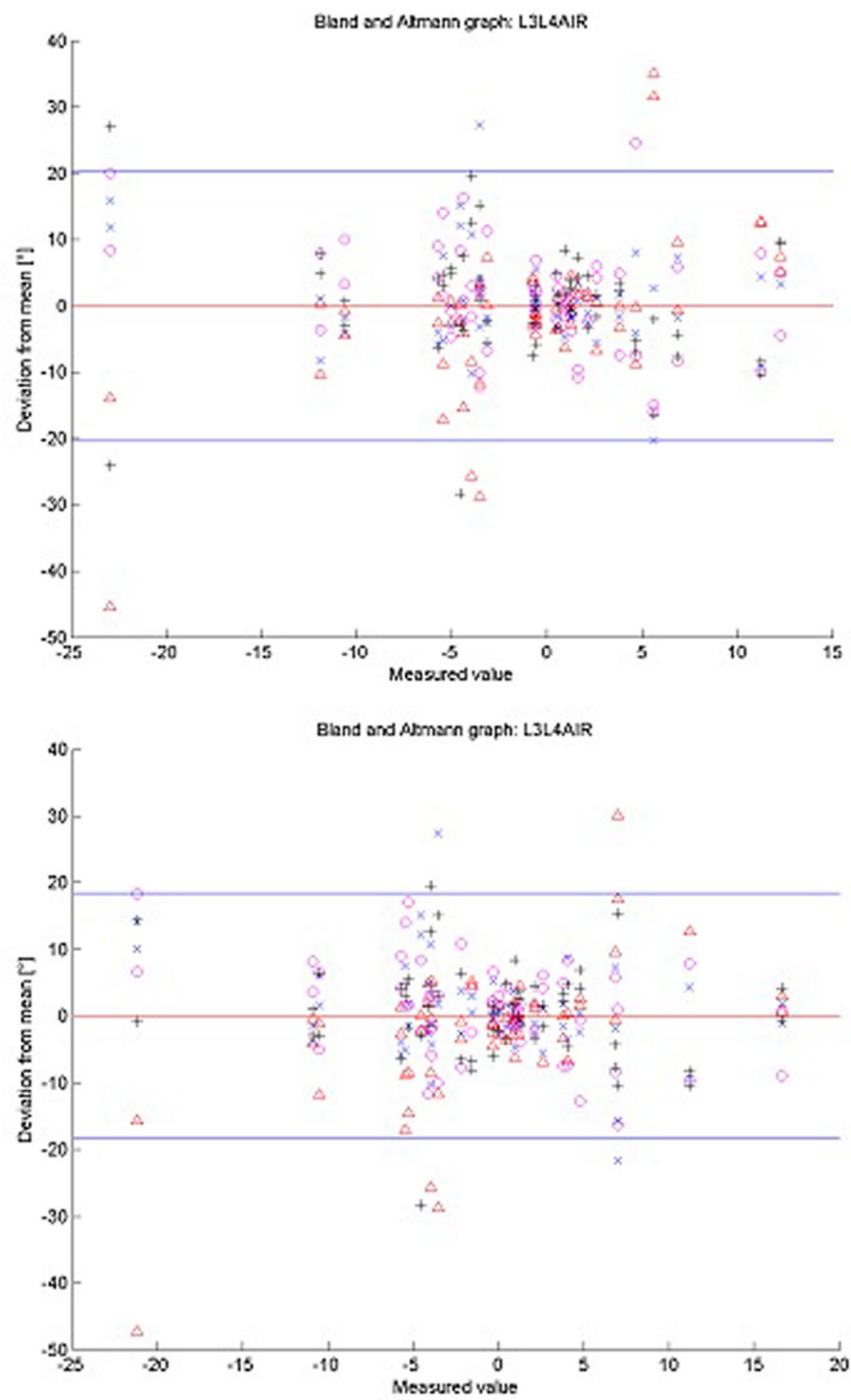

$\Delta$ corresponds to obsenver measurements, + to observer $2, x$ to observer 3 , o to observer 4 . Each observer performed two times the measurements. hypotheses for the genesis of degenerative scoliosis is disc degeneration with increased axial vertebral and intervertebral rotation. Therefore, transverse plane analysis at early stage of the scoliosis seems of particular interest, to diagnose patients with high risk of progression.
Stereoradiography can be used for many applications; its usefulness in scoliosis and sagittal plane analysis in pediatrics has been highlighted, with its biplanar acquisition system in the standing position and its ability to determine relationships among the different spinal segments with 3D 
Table 1 Results of the descriptive analysis of the Cobb angle (in degrees) and AVR apex (in degrees)

Table 2 Results of the descriptive analysis of transverse plane parameters (in degrees)

\begin{tabular}{lcccccc}
\hline & Cobb 1 & Cobb 2 & Cobb 3 & AVR cobb 1 & AVR cobb 2 & AVR cobb 3 \\
\hline Mean & 12.1 & 25.1 & 27.6 & 4.9 & 8.7 & 19.5 \\
SD & 12.3 & 18.9 & 19.9 & 4.1 & 9.4 & 20.3 \\
Min & 0.0 & 0.1 & 0.0 & 0.0 & 0.1 & 0.0 \\
Max & 49.1 & 65.7 & 79.2 & 19.4 & 47.9 & 98.9 \\
\hline
\end{tabular}

\begin{tabular}{llcccc}
\hline & Main cobb & AVR main cobb & Torsion index & Upper AIR & Lower AIR \\
\hline Mean & 31.0 & 15.7 & 29.9 & 6.2 & 4.8 \\
SD & 18.3 & 15.7 & 25.2 & 5.6 & 4.5 \\
Min & 10.2 & 0.1 & 1.4 & 0.0 & 0.0 \\
Max & 71.8 & 98.9 & 190 & 26.9 & 21.1 \\
\hline
\end{tabular}

Table 3 Results of the descriptive analysis of sagittal parameters (in degrees)

\begin{tabular}{lllrrrr}
\hline & PI & SS & \multicolumn{1}{c}{ PT } & L1S1 & T4T12 & T1T12 \\
\hline Mean & 54.9 & 34.4 & 20.5 & 47.0 & 31.7 & 38.2 \\
SD & 12.4 & 10.8 & 10.8 & 16.6 & 17.4 & 16.1 \\
Min & 35.0 & 16.7 & -0.1 & 4.2 & -7.8 & -2.2 \\
Max & 83.3 & 60.1 & 45.9 & 79.2 & 67.8 & 70.9 \\
\hline
\end{tabular}

analysis [36]. Several studies on adolescent idiopathic scoliosis demonstrated the prognostic importance of transverse plane analysis [29, 30, 35]. One prospective study comparing adolescents with the same age and Cobb angle showed that patients with the greater axial intervertebral rotation had a worst evolution with an increasing deformity. These measurements could be performed on MRI and CT scan; however, it involves a higher radiation dose [37] and these exams are performed in supine position, which might not allow analysis of anatomic factors underlying pain or loss of function in upright position. The low-dose biplanar stereoradiographic system allows upright positioning with 6-9 times less radiation doses than conventional X-rays [38]. Few authors analyzed reproducibility of 3D measurements in AIS [18, 23, 29, 30, 39]. To the best of our knowledge, however, only two studies focused on ASD, only one of which analyzed axial rotation using the biplanar X-rays system [23, 31]. Comparison between biplanar X-rays and CT scan measurements was performed in a recent study [40]. Authors concluded that vertebral rotation results were not significantly different between biplanar X-rays and CT scan. However, this study was performed on a small cohort (only seven patients included).

In the current study, 3D measurements were found reliable for Cobb angle and sagittal parameters. AIR reproducibility was less accurate for the lumbar levels than thoracic levels, even by changing the contrast and luminosity to better visualize the vertebrae. The present results were close with previously reported values for AIS with standard deviation reliability of $\pm 1.6^{\circ}$ for coronal, $\pm 2.0^{\circ}$ for sagittal and $\pm 3.8^{\circ}$ for apical vertebral rotation [17]. $S_{\mathrm{R}}$ and ICC values gave complementary informations. ICC values corresponded to good, moderate and poor reproducibility for, respectively, AVR apex, torsion index or upper AIR, and lower AIR. Nevertheless, Bland and Altman emphasized the limitations of ICC evaluation, while $S_{\mathrm{R}}$ allows a quantitative estimation of the measurements uncertainty, as $\pm 2 S_{\mathrm{R}}$ [27]. In the current study, higher uncertainty of the lower AIR than upper AIR could be explained by the difficulty to see the lumbo-sacral area in these older patients
Table 4 Results $S_{\mathrm{R}}$ and ICC for transverse plane parameters

\begin{tabular}{lllll}
\hline & AVR main curve & Torsion index & Upper AIR & Lower AIR \\
\hline Cobb $<30^{\circ}(n=14)$ & & & & \\
$\mathrm{S}_{\mathrm{R}}\left(^{\circ}\right)$ & 7.8 & 9.6 & 4.5 & 4.9 \\
$\mathrm{ICC}$ INTER & 0.8 & 0.745 & 0.731 & 0.427 \\
Cobb $>30^{\circ}(n=16)$ & & & & \\
$S_{\mathrm{R}}\left({ }^{\circ}\right)$ & 20.3 & 5.4 & 6.4 \\
$\mathrm{ICC}$ INTER & 0.8 & 0.561 & 0.46 & 0.358 \\
Entire cohort $(n=30)$ & & & 5.3 \\
$S_{\mathrm{R}}\left({ }^{\circ}\right)$ & 8.3 & 14.2 & 5.8 & 0.392 \\
ICC INTER & 0.762 & 0.653 & 0.595 & \\
\hline
\end{tabular}


(Table 4). In the setting of lumbar degenerative scoliosis, rotatory subluxation often occurs at L3L4 and is associated with a bad visibility of the dislocated level $[6,32]$. Moreover, the range of AIR in the current study was the largest at L3L4. Another important finding is the decrease repeatability and reproducibility as Cobb angle increases as shown in Table 4. These findings are concordant with Barsanti's results using a torsionmeter [41]. He also noticed higher measurement errors for higher deformity. Of note, without aberrant error due to observer, there was a slight improvement in lumbar AIR measurement of $2^{\circ}$ but not obvious change in coronal and sagittal intervertebral rotation. As a matter of fact, attention of the observer while doing 3D analysis is essential as shown with Bland and Altman graph, since some errors inherent to observer should be avoided (Fig. 4). Overall, these results highlighted the validity of transverse plane analysis for mild deformity and suggested that stereoradiography might be an useful tool for the follow-up of mild deformity: to assess the worsening of the coronal and sagittal curves as well as the rotation.

The current study involves certain limitations. The number of patients is moderate and influence of body mass index on accuracy of the measurements was not assessed.

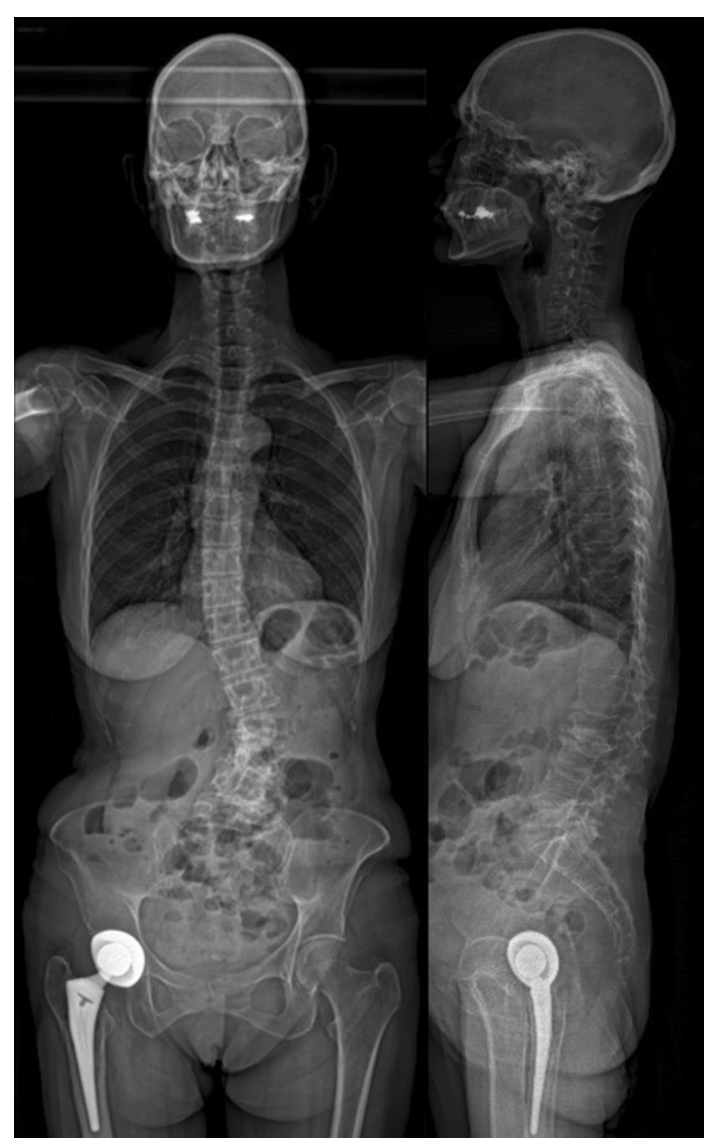

Fig. 4 Example of patient with risk of measurement errors (poor visibility at L3L4)
Another point is that detailed radiographic analysis of anatomic structures (foramina, facet joint) was difficult for some patients, while degenerative changes such as disc collapse and listhesis were well distinguished. These difficulties could be explained by the severe deformity associated with osteoarthritis and osteoporosis, frequently observed in ASD. Moreover, full-spine 3D reconstruction of ASD patients is time consuming (15-25 min). This issue could be avoided using a "fast spine" protocol but at the cost of less accurate measurements for some parameters. Work is in progress for improvement of the reconstruction method taking more benefit of image processing. For example, a recently developed method offers the possibility of reconstructing body shape in addition to the skeleton with stereoradiography [43]. Such advances should yield improved reliability in the near future.

\section{Conclusion}

This study investigated reproducibility and repeatability of 3D measurements in the setting of ASD patients. Threedimensional analysis was reliable for spinal parameters in the entire cohort. While sagittal and coronal parameters demonstrated a high reliability, transverse plane parameters reliability was more accurate when Cobb angle was below $30^{\circ}$. These lower agreement values might be explained by the severity of deformity and difficulty to distinguish detailed cortical lines due to low bone density. Nevertheless, despite more complex deformity, current results were close to previously published reproducibility studies.

Using biplanar stereoradiographic, 3D reconstructions of the spine might be interesting to better understand 3D spinal deformity in standing position. Thus, it could help the surgeon to anticipate onset of rotatory subluxation while assessing the axial intervertebral rotation evolution for patients with small deformity. Likewise, transverse plane analysis could give interesting information on these mild deformities to prevent for the curve progression and choose the best delay for surgical treatment, depending on the severity of the axial rotation.

Compliance with ethical standards

Conflict of interest None of the authors has any potential conflict of interest.

\section{References}

1. Perdriolle R, Vidal J (1987) Morphology of scoliosis: three-dimensional evolution. Orthopedics 10(6):909-915

2. Cobb JR (1960) The problem of the primary curve. J Bone Joint Surg Am 42-A:1413-1425 
3. Labelle H, Aubin C-E, Jackson R, Lenke L, Newton P, Parent S (2011) Seeing the spine in 3D: how will it change what we do? J Pediatr Orthop 31(1 Suppl):S37-S45

4. Mehta MH (1973) Radiographic estimation of vertebral rotation in scoliosis. J Bone Joint Surg Br 55(3):513-520

5. Lafage V, Schwab F, Patel A, Hawkinson N, Farcy J-P (2009) Pelvic tilt and truncal inclination: two key radiographic parameters in the setting of adults with spinal deformity. Spine 34(17):E599-E606

6. Schwab FJ, Smith VA, Biserni M, Gamez L, Farcy J-PC, Pagala M (2002) Adult scoliosis: a quantitative radiographic and clinical analysis. Spine 27(4):387-392

7. Glassman SD, Bridwell K, Dimar JR, Horton W, Berven S, Schwab F (2005) The impact of positive sagittal balance in adult spinal deformity. Spine 30(18):2024-2029

8. Nash CL Jr, Moe JH (1969) A study of vertebral rotation. J Bone Joint Surg Am 51(2):223-229

9. Perdriolle R, Vidal J (1981) A study of scoliotic curve. The importance of extension and vertebral rotation (author's transl). Rev Chir Orthopédique Réparatrice Appar Mot 67(1):25-34

10. Stokes IA, Bigalow LC, Moreland MS (1986) Measurement of axial rotation of vertebrae in scoliosis. Spine 11(3):213-218

11. Weiss HR (1995) Measurement of vertebral rotation: Perdriolle versus Raimondi. Eur Spine J Off Publ Eur Spine Soc Eur Spinal Deform Soc Eur Sect Cerv Spine Res Soc 4(1):34-38

12. Skalli W, Lavaste F, Descrimes JL (1995) Quantification of threedimensional vertebral rotations in scoliosis: what are the true values? Spine 20(5):546-553

13. Bone CM, Hsieh GH (2000) The risk of carcinogenesis from radiographs to pediatric orthopaedic patients. J Pediatr Orthop 20(2):251-254

14. Dubousset J, Charpak G, Dorion I, Skalli W, Lavaste F, Deguise J et al (2005) A new 2D and 3D imaging approach to musculoskeletal physiology and pathology with low-dose radiation and the standing position: the EOS system. Bull Académie Natl Médecine 189(2):287-297 (discussion 297-300)

15. Courvoisier A, Drevelle X, Vialle R, Dubousset J, Skalli W (2013) 3D analysis of brace treatment in idiopathic scoliosis. Eur Spine J Off Publ Eur Spine Soc Eur Spinal Deform Soc Eur Sect Cerv Spine Res Soc 22(11):2449-5524

16. Ilharreborde B, Dubousset J, Skalli W, Mazda K (2013) Spinal penetration index assessment in adolescent idiopathic scoliosis using EOS low-dose biplanar stereoradiography. Eur Spine J Off Publ Eur Spine Soc Eur Spinal Deform Soc Eur Sect Cerv Spine Res Soc 22(11):2438-2444

17. Ilharreborde B, Steffen JS, Nectoux E, Vital JM, Mazda K, Skalli W et al (2011) Angle measurement reproducibility using EOS three-dimensional reconstructions in adolescent idiopathic scoliosis treated by posterior instrumentation. Spine 36(20):E1306E1313

18. Kalifa G, Charpak Y, Maccia C, Fery-Lemonnier E, Bloch J, Boussard JM et al (1998) Evaluation of a new low-dose digital $\mathrm{X}$-ray device: first dosimetric and clinical results in children. Pediatr Radiol 28(7):557-561

19. Dubousset J, Charpak G, Skalli W, Kalifa G, Lazennec J-Y (2007) EOS stereo-radiography system: whole-body simultaneous anteroposterior and lateral radiographs with very low radiation dose. Rev Chir Orthopédique Réparatrice Appar Mot 93(6 Suppl):141-143

20. Faro FD, Marks MC, Pawelek J, Newton PO (2004) Evaluation of a functional position for lateral radiograph acquisition in adolescent idiopathic scoliosis. Spine 29(20):2284-2289

21. Pasha S, Capraro A, Cahill PJ, Dormans JP, Flynn JM (2016) Biplanar spinal stereoradiography of adolescent idiopathic scoliosis: considerations in 3D alignment and functional balance. Eur Spine J 25(10):3234-3241
22. Cobb JR (1947) Progress in orthopedic surgery for 1945; conditions involving the spine and thorax, exclusive of those in the lower part of the back. Arch Surg 55(1):76-87

23. Steib J-P, Dumas R, Mitton D, Skalli W (2004) Surgical correction of scoliosis by in situ contouring: a detorsion analysis. Spine 29(2):193-919

24. Humbert L, De Guise JA, Aubert B, Godbout B, Skalli W (2009) $3 \mathrm{D}$ reconstruction of the spine from biplanar X-rays using parametric models based on transversal and longitudinal inferences. Med Eng Phys 31(6):681-687

25. Sangole A, Aubin C-E, Labelle H, Lenke L, Jackson R, Newton P et al (2010) The central hip vertical axis: a reference axis for the Scoliosis Research Society three-dimensional classification of idiopathic scoliosis. Spine 35(12):E530-E534

26. Pomero V, Mitton D, Laporte S, de Guise JA, Skalli W (2004) Fast accurate stereoradiographic 3D-reconstruction of the spine using a combined geometric and statistic model. Clin Biomech Bristol Avon 19(3):240-247

27. Bland JM, Altman DG (1995) Comparing methods of measurement: why plotting difference against standard method is misleading. Lancet Lond Engl 346(8982):1085-1087

28. Bartko JJ (1966) The intraclass correlation coefficient as a measure of reliability. Psychol Rep 19(1):3-11

29. Courvoisier A, Drevelle X, Dubousset J, Skalli W (2013) Transverse plane 3D analysis of mild scoliosis. Eur Spine J Off Publ Eur Spine Soc Eur Spinal Deform Soc Eur Sect Cerv Spine Res Soc 22(11):2427-2432

30. Ilharreborde B, Dubousset J, Le Huec J-C (2014) Use of EOS imaging for the assessment of scoliosis deformities: application to postoperative 3D quantitative analysis of the trunk. Eur Spine J Off Publ Eur Spine Soc Eur Spinal Deform Soc Eur Sect Cerv Spine Res Soc 23(Suppl 4):S397-S405

31. Steffen J-S, Obeid I, Aurouer N, Hauger O, Vital J-M, Dubousset $\mathrm{J}$ et al (2010) 3D postural balance with regard to gravity line: an evaluation in the transversal plane on 93 patients and 23 asymptomatic volunteers. Eur Spine J Off Publ Eur Spine Soc Eur Spinal Deform Soc Eur Sect Cerv Spine Res Soc 19(5):760-767

32. Ferrero E, Lafage R, Challier V, Diebo B, Guigui P, Mazda K et al (2015) Clinical and stereoradiographic analysis of adult spinal deformity with and without rotatory subluxation. Orthop Traumatol Surg Res OTSR 101(5):613-618

33. Hong J-Y, Suh S-W, Easwar TR, Modi HN, Yang J-H, Park J-H (2011) Evaluation of the three-dimensional deformities in scoliosis surgery with computed tomography: efficacy and relationship with clinical outcomes. Spine 36(19):E1259-E1265

34. Nault M-L, Mac-Thiong J-M, Roy-Beaudry M, deGuise J, Labelle H, Parent S (2013) Three-dimensional spine parameters can differentiate between progressive and nonprogressive patients with AIS at the initial visit: a retrospective analysis. J Pediatr Orthop 33(6):618-623

35. Nault M-L, Mac-Thiong J-M, Roy-Beaudry M, Turgeon I, Deguise J, Labelle H et al (2014) Three-dimensional spinal morphology can differentiate between progressive and nonprogressive patients with adolescent idiopathic scoliosis at the initial presentation: a prospective study. Spine 39(10):E601-E606

36. Melhem E, Assi A, El Rachkidi R, Ghanem I (2016) EOS $\left({ }^{\circledR}\right)$ biplanar X-ray imaging: concept, developments, benefits, and limitations. J Child Orthop 10(1):1-14

37. Ilharreborde B, Ferrero E, Alison M, Mazda K (2016) EOS microdose protocol for the radiological follow-up of adolescent idiopathic scoliosis. Eur Spine J 25(2):526-531. doi: 10.1007/ s00586-015-3960-8

38. Deschênes S, Charron G, Beaudoin G, Labelle H, Dubois J, Miron M-C et al (2010) Diagnostic imaging of spinal deformities: 
reducing patients radiation dose with a new slot-scanning X-ray imager. Spine 35(9):989-994

39. Gille O, Champain N, Benchikh-El-Fegoun A, Vital J-M, Skalli W (2007) Reliability of 3D reconstruction of the spine of mild scoliotic patients. Spine 32(5):568-573

40. Al-Aubaidi Z, Lebel D, Oudjhane K, Zeller R (2013) Threedimensional imaging of the spine using the EOS system: is it reliable? A comparative study using computed tomography imaging. J Pediatr Orthop Part B 22(5):409-412

41. Barsanti CM, deBari A, Covino BM (1990) The torsion meter: a critical review. J Pediatr Orthop 10(4):527-531
42. ISO 5725-2:1994/Cor 1 (2002) Accuracy (trueness and precision) of measurement methods and results-part 2: basic method for the determination of repeatability and reproducibility of a standard measurement method: international organization for standardization. http://www.iso.org. Accessed 22 Dec 1994

43. Nérot A, Choisne J, Amabile C, Travert C, Pillet H, Wang X et al (2015) A 3D reconstruction method of the body envelope from biplanar X-rays: evaluation of its accuracy and reliability. J Biomech 48(16):4322-4326 